Article

\title{
Moho Density Contrast in Central Eurasia from GOCE Gravity Gradients
}

\author{
Mehdi Eshagh ${ }^{1}$, Matloob Hussain ${ }^{1,2}$, Robert Tenzer ${ }^{3,4, *}$ and Mohsen Romeshkani ${ }^{5}$ \\ 1 Department of Engineering Science, University West, Trollhättan 46186, Sweden; \\ mehdi.eshagh@hv.se (M.E.); mutloob.hussain@hv.se (M.H.) \\ 2 Department of Earth Sciences, Quaid-i-Azam University, Islamabad 45320, Pakistan \\ 3 The Key Laboratory of Geospace Environment and Geodesy, Wuhan University, Wuhan 430079, China \\ 4 New Technologies for the Information Society (NTIS), University of West Bohemia, Plzen 30614, \\ Czech Republic \\ 5 School of Surveying and Geospatial Engineering, College of Engineering, University of Tehran, \\ Tehran 14395-515, Iran; romeshkani@ut.ac.ir \\ * Correspondence: rtenzer@sgg.whu.edu.cn; Tel.: +86-27-6877-8649
}

Academic Editors: Cheinway Hwang, Wenbin Shen, C.K. Shum, Stéphane Calmant and Prasad S. Thenkabail Received: 1 February 2016; Accepted: 4 May 2016; Published: 17 May 2016

\begin{abstract}
Seismic data are primarily used in studies of the Earth's inner structure. Since large parts of the world are not yet sufficiently covered by seismic surveys, products from the Earth's satellite observation systems have more often been used for this purpose in recent years. In this study we use the gravity-gradient data derived from the Gravity field and steady-state Ocean Circulation Explorer (GOCE), the elevation data from the Shuttle Radar Topography Mission (SRTM) and other global datasets to determine the Moho density contrast at the study area which comprises most of the Eurasian plate (including parts of surrounding continental and oceanic tectonic plates). A regional Moho recovery is realized by solving the Vening Meinesz-Moritz's (VMM) inverse problem of isostasy and a seismic crustal model is applied to constrain the gravimetric solution. Our results reveal that the Moho density contrast reaches minima along the mid-oceanic rift zones and maxima under the continental crust. This spatial pattern closely agrees with that seen in the CRUST1.0 seismic crustal model as well as in the KTH1.0 gravimetric-seismic Moho model. However, these results differ considerably from some previously published gravimetric studies. In particular, we demonstrate that there is no significant spatial correlation between the Moho density contrast and Moho deepening under major orogens of Himalaya and Tibet. In fact, the Moho density contrast under most of the continental crustal structure is typically much more uniform.
\end{abstract}

Keywords: density contrast; satellite gravity missions; Eurasia; Moho; terrain model; Tibet

\section{Introduction}

The Earth's satellite observation systems have been used in various geoscience studies of the Earth's interior and processes. The global elevation models derived from processing the Shuttle Radar Topography Mission (SRTM) data are used, for instance, to compute the topographic gravity correction in context of the gravimetric interpretation of sedimentary basins as well as other subsurface density structures and/or density interfaces. Apart from climatic studies, the satellite-altimetry observations are also used to determine the marine gravity data. Since the marine gravity field is highly spatially correlated with the ocean-floor relief at a certain wavelength-band, these gravity data are used to predict the ocean-floor depths [1-3]. By analogy with applying the topographic gravity correction, the ocean-floor depths are used to compute the bathymetric-stripping gravity correction. The satellite-gravity observations have also been used to interpret the Earth's inner structure. This 
becomes particularly possible with the advent of three dedicated satellite-gravity missions, namely the Challenging Mini-satellite Payload (CHAMP) [4-6], the Gravity Recovery and Climate Experiment (GRACE) [7] and the Gravity field and steady-state Ocean Circulation Explorer (GOCE) [8,9]. The latest gravitational models derived from these satellite missions have a spatial resolution about 66 to $80 \mathrm{~km}$ (in terms of a half-wavelength). Moreover, these gravitational models have (almost) global and homogeneous coverage with well-defined stochastic properties.

Methods for a gravimetric Moho recovery from topographic, bathymetric, gravitational and crustal structure models have been developed and applied by a number of authors (e.g., [10-17]). In these studies, a uniform Moho density contrast has often been assumed. The results of seismic studies, however, revealed that the Moho density contrast varies significantly. The continental Moho density contrast $200 \mathrm{~kg} \cdot \mathrm{m}^{-3}$ in Canada was reported by [18]. Regional seismic studies [19,20] based on using the wave-receiver functions indicate that the density contrast regionally varies as much as from $160 \mathrm{~kg} \cdot \mathrm{m}^{-3}$ (for the mafic lower crust) to $440 \mathrm{~kg} \cdot \mathrm{m}^{-3}$ (for the felsic lower crust), with an apparently typical value $440 \mathrm{~kg} \cdot \mathrm{m}^{-3}$ for the craton. The Moho density contrast information is also included in the global crustal model CRUST1.0 [21]. According to this seismic model, the Moho density contrast (computed as the density difference between the upper mantle and the lower crust) globally varies between 10 and $610 \mathrm{~kg} \cdot \mathrm{m}^{-3}$, while this range is between 340 and $790 \mathrm{~kg} \cdot \mathrm{m}^{-3}$ when computed with respect to the reference crustal density $2670 \mathrm{~kg} \cdot \mathrm{m}^{-3}$ (as often used in gravimetric studies).

An attempt to incorporate the variable Moho density contrast in gravimetric methods for a determination of the Moho depth has been done by some authors. [22] took into consideration the lateral as well as radial density variation within the crystalline crustal layers and simultaneously adjusted all the densities and estimated the Moho depth. A method for a simultaneous determination of the Moho depth and density contrast developed by [23] was based on solving the Vening Meinesz-Moritz's (VMM) inverse problem of isostasy [24-27]. This method was applied to estimate the Moho parameters globally and regionally (e.g., [28]). It was also demonstrated that the gravimetric determination of the Moho depth is more accurate when using the variable Moho density contrast [29]. The gravimetric results confirmed large variations of the Moho density contrast. According to [23], the Moho density contrast varies globally from $81.5 \mathrm{~kg} \cdot \mathrm{m}^{-3}$ (in the Pacific region) to $988 \mathrm{~kg} \cdot \mathrm{m}^{-3}$ (beneath the Tibetan Plateau). A similar range of values between 82 and $965 \mathrm{~kg} \cdot \mathrm{m}^{-3}$ was reported by [30]. It was also shown [31] that the Moho density contrast under the oceanic crust is highly spatially correlated with the ocean-floor age.

The gravimetrically-determined Moho density contrast [23,30] differs significantly from the CRUST1.0 values especially under major orogens in central Asia. To examine this aspect, we investigated the Moho density contrast at the study area which comprises most of the Eurasian tectonic plate and includes also surrounding oceanic and continental plates. For this purpose, we developed and applied a novel approach which utilizes a least-squares technique for solving the condition equations based on minimizing residuals between the gravimetric and seismic Moho parameters, particularly specified for a product of the Moho depth and density contrast.

\section{Method}

A functional relation between the refined gravity data and the Moho density contrast is defined here by means of solving the VMM inverse problem of isostasy. We note that this functional relation was already derived by [26], but using a slightly different approach than that presented here. We further extend this definition for finding the Moho density contrast from the in-orbit GOCE gravity-gradient data. We then propose a least-squares technique for solving the VMM problem based on combining the vertical gravity gradients and seismic model and finally investigate a spatial behavior of the integral kernel used for a regional gravity-gradient data inversion. 


\subsection{Moho Density Contrast from Gravity Disturbance}

The VMM isostatic problem was formulated in the following generic form $[26,27,32]$

$$
-G R \iint_{\sigma} \Delta \rho K(\psi, T) d \sigma=\delta g^{i}
$$

where $G$ is the Newton's gravitational constant, $R$ is the Earth's mean radius, $\Delta \rho$ is the (variable) Moho density contrast, $T$ is the Moho depth, $\delta g^{i}$ is the isostatic gravity disturbance, $\sigma$ is the unit sphere, and $d \sigma$ is the surface integration element. The integral kernel $K$ in Equation (1) is a function of the spherical distance $\psi$ and the Moho depth T. Its spectral representation reads [26]

$$
K(\psi, T)=\sum_{n=0}^{\infty} \frac{n+1}{n+3}\left[1-\left(1-\frac{T}{R}\right)^{n+3}\right] P_{n}(\cos \psi)
$$

where $P_{n}$ is the Legendre polynomial of degree $n$.

The isostatic gravity disturbances $\delta g^{i}$ on the right-hand side of Equation (1) are computed from the gravity disturbances $\delta g$ by subtracting the gravitational contributions of topography $g^{\mathrm{T}}$, bathymetry $g^{\mathrm{B}}$ and sediments $g^{\mathrm{S}}$ and adding the compensation attraction $A_{\mathrm{CO}}$. Hence

$$
\delta g^{i}=\delta g-g^{\mathrm{T}}-g^{\mathrm{B}}-g^{\mathrm{S}}+A_{\mathrm{C} 0}
$$

The compensation attraction $A_{C 0}$ in Equation (3) is computed from [26]

$$
A_{C 0}=\frac{4 \pi G \Delta \rho_{0} R}{3}\left[\left(1-\frac{T_{0}}{R}\right)^{3}-1\right] \approx-4 \pi G \Delta \rho_{0} T_{0}
$$

where $T_{0}$ and $\Delta \rho_{0}$ are mean values of the Moho depth and density contrast respectively.

To solve the VMM problem for finding the Moho density contrast $\Delta \rho$, we first simplified the integral kernel $K$ in Equation (2). By applying a Taylor series (up to a first-order term) to $(1-T / R)^{n+3}$, we get

$$
K(\psi, T)=\frac{T}{R} \sum_{n=0}^{\infty}(n+1) P_{n}(\cos \psi)
$$

Substitution from Equation (5) to Equation (1) then yields

$$
-G \sum_{n=0}^{\infty}(n+1) \iint_{\sigma}(\Delta \rho T) P_{n}(\cos \psi) d \sigma=\delta g^{i}
$$

The surface integral on the left-hand side of Equation (6) is defined in terms of the Laplace harmonic $(\Delta \rho T)_{n}$ as follows [33]

$$
\iint_{\sigma}(\Delta \rho T) P_{n}(\cos \psi) d \sigma=\frac{4 \pi}{2 n+1}(\Delta \rho T)_{n}
$$

Inserting from Equation (7) to Equation (6), we obtained the following relation

$$
-4 \pi G \sum_{n=0}^{\infty} \frac{n+1}{2 n+1}(\Delta \rho T)_{n}=\delta g^{i}
$$

The coefficients $(\Delta \rho T)_{n}$ in Equation (8) are generated from the Laplace harmonics $\delta g_{n}^{i}$ of the isostatic gravity field as follows

$$
(\Delta \rho T)_{n}=-\frac{A_{C 0}}{4 \pi G} \delta_{n 0}-\frac{1}{4 \pi G} \frac{2 n+1}{n+1}\left(\delta g_{n}-g_{n}^{\mathrm{T}}-g_{n}^{\mathrm{B}}-g_{n}^{\mathrm{S}}\right)
$$


where $g_{n}^{\mathrm{T}}, g_{n}^{\mathrm{B}}$ and $g_{n}^{\mathrm{S}}$ are, respectively, the Laplace harmonics of the topographic, bathymetric and sediment gravitational contributions, and $\delta_{n 0}$ is Kronecker's delta.

The expression in Equation (9) is finally rearranged into the following form

$$
\Delta \rho T=\Delta \rho_{0} T_{0}-\frac{1}{4 \pi G} \sum_{n=0}^{\infty} \frac{2 n+1}{n+1}\left(\delta g_{n}-g_{n}^{\mathrm{T}}-g_{n}^{\mathrm{B}}-g_{n}^{\mathrm{S}}\right)
$$

As seen in Equation (10), the gravity disturbances and gravity corrections are computed in the spectral domain, while the compensation attraction $A_{C 0}$ is computed approximately according to Equation (4) from the a priori values of the Moho depth and density contrast.

\subsection{Moho Density Contrast from Gravity Gradient}

The functional model for finding the Moho density contrast in Equation (10) is now redefined for the vertical gravity gradient (i.e., the second-order radial derivative of the disturbing potential $V_{r r}$ ). It is worth mentioning that results (not presented here) revealed that the contribution of horizontal gravity-gradient components on the Moho parameters is completely negligible.

The relation between the Laplace harmonics $V_{r r, n}$ and $\delta g_{n}$ reads

$$
\delta g_{n}=\frac{r^{2}}{R} \frac{1}{(n+2)}\left(\frac{r}{R}\right)^{n+1} V_{r r, n}
$$

where $r$ is the geocentric radius. The application of a scaling factor $r / R$ in Equation (11) allows solving the VMM problem for the gravity-gradient data at an arbitrary point on or above the geoid. Note that the generic expression in Equation (1) defines the VMM problem only on the geoid surface (approximated by a sphere of radius $R$ ). The downward continuation of gravity data observed at the topographic surface (or satellite altitudes) onto the geoid is then required in prior of solving the VMM problem.

Substitution from Equation (11) to Equation (10) yields

$$
\Delta \rho T=\Delta \rho_{0} T_{0}-\frac{1}{4 \pi G}\left[\sum_{n=0}^{\infty} \frac{2 n+1}{n+1}\left(-g_{n}^{\mathrm{T}}-g_{n}^{\mathrm{B}}-g_{n}^{\mathrm{S}}\right)+W\right]
$$

where the parameter $W$ is defined by

$$
W=\frac{r^{2}}{R} \sum_{n=0}^{\infty} \frac{2 n+1}{(n+1)(n+2)}\left(\frac{r}{R}\right)^{n+1} V_{r r, n}
$$

The Laplace harmonics $W_{n}$ of the parameter $W$ are generated from the respective harmonics $V_{r r, n}$ of the vertical gravity gradient $V_{r r}$ using the following expression

$$
W_{n} R \frac{(n+1)(n+2)}{(2 n+1)}\left(\frac{R}{r}\right)^{n+1}=r^{2} V_{r r, n}
$$

Alternatively, the Laplace harmonics $W_{n}$ can be defined in the following form [33]

$$
W_{n}=\frac{2 n+1}{4 \pi} \iint_{\sigma} W P_{n}(\cos \psi) d \sigma
$$

Substituting from Equation (15) back to Equation (14) and applying further simplifications, we arrived at

$$
\frac{R}{4 \pi} \iint_{\sigma} W L(r, \psi) d \sigma=r^{2} V_{r r}
$$


where the integral kernel $L$ reads

$$
L(r, \psi)=\sum_{n=0}^{\infty}(n+1)(n+2)\left(\frac{R}{r}\right)^{n+1} P_{n}(\cos \psi)
$$

A practical computation of the Moho density contrast is realized in two numerical steps. The unknown parameters $W$ are first computed by solving the inverse to the system of observation equations. These observation equations are formed by applying a discretization to the integral equation in Equation (16). The estimated parameters $W$ are then used to compute the Moho density contrast according to the definition given in Equation (12).

\subsection{Combined Model}

The functional model from Equation (16) is now used to formulate a method for finding the Moho density contrast by combining the gravity-gradient data and seismic crustal model. For this purpose we use the a priori information on the Moho depth and density contrast from an available seismic crustal model to define the condition equation for solving the VMM problem. A least-squares technique is then applied to estimate the Moho density contrast from the gravity-gradient data. Since the accuracy of seismic data is typically not provided, we do not apply a stochastic model.

The condition equation is defined in the following form

$$
\Delta \rho T-\Delta \rho_{0} T_{0}+M=0
$$

where the parameter $M$ is defined by

$$
M=\frac{1}{4 \pi G}\left[\sum_{n=0}^{\infty} \frac{2 n+1}{n+1}\left(-g_{n}^{\mathrm{T}}-g_{n}^{\mathrm{B}}-g_{n}^{\mathrm{S}}\right)+W\right]
$$

The condition equation in Equation (18) assumes that the differences (i.e., residuals) between the gravimetric and seismic Moho parameters are minimized by means of applying a least-squares technique. The system of condition equations then becomes

$$
\mathbf{B}=\left[\begin{array}{lllll}
T & \Delta \rho & -T_{0} & -\Delta \rho_{0} & 1
\end{array}\right]
$$

and

$$
\mathbf{w}=0-\Delta \rho T+\Delta \rho_{0} T_{0}+M
$$

The system of condition equations can uniquely be solved by applying the minimum-norm condition. Hence, we have

$$
\hat{\mathbf{v}}=\left(\begin{array}{c}
\delta \hat{T} \\
\delta \Delta \hat{\rho} \\
\delta \hat{T}_{0} \\
\delta \Delta \hat{\rho}_{0} \\
\delta \hat{M}
\end{array}\right)=\mathbf{B}^{\mathrm{T}}\left(\mathbf{B} \mathbf{B}^{\mathrm{T}}\right)^{-1} \mathbf{w}
$$

The solution of Equation (22) yields the correction terms to the Moho parameters.

\subsection{Kernel Behavior}

To compute the parameter $W$, the integral equation in Equation (16) is discretized and then solved numerically. The dependence of result on the integration domain can be investigated from a spatial behavior of the integral kernel $L$. The gravity inversion could be localized if the integral kernel attenuates quickly with an increasing spherical distance [34,35]. The inversion is then carried out using only data within the near zone, while the far-zone contribution is disregarded. The near zone is chosen so that truncation errors due to disregarding the far-zone contribution are negligible. 
A spatial behavior of the integral kernel $L$ is illustrated in Figure 1. The kernel attenuates very quickly already at 2 arc-deg of the spherical distance with nearly zero values at 4 arc-deg. The near-zone limit $\psi \leqslant 4$ arc-deg thus sufficiently reduces truncation errors.

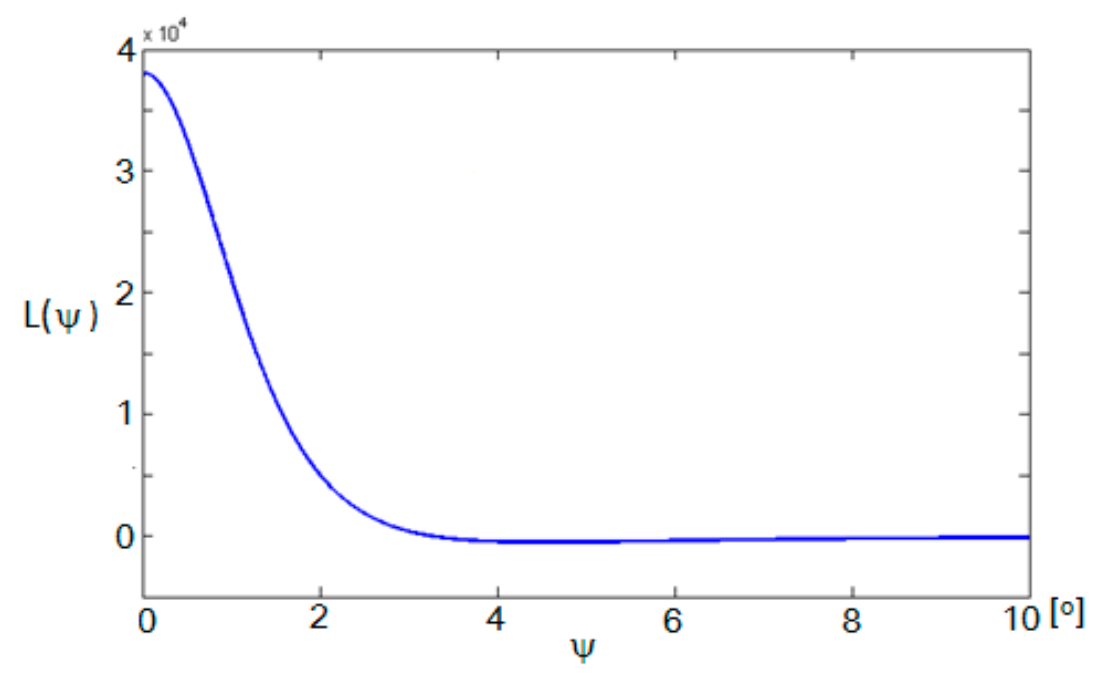

Figure 1. Integral kernel $L$ (for the mean satellite attitude $250 \mathrm{~km}$ ).

\section{Numerical Realization}

In this section we begin with a brief tectonic classification of the study area, then specify input data and applied methods and finally present and validate results.

\subsection{Study Area and Tectonic Setting}

The regional study area is bounded by the parallels 0 and 70 arc-deg of the northern latitude and the meridians 40 and 120 arc-deg of the eastern longitude. A tectonic configuration of this study area comprises parts of the Eurasian, Indian, Arabian, African, Amur and Sunda plates including the Tibetan, Iranian and Yangtze tectonic blocks (Figure 2a). It comprises zones of the compressional, extensional and strike-slip tectonism. The most prominent tectonic feature is the active continent-to-continent collision of the Indian plate with the Tibetan block, which has been responsible for the uplift of Himalaya. Tomographic evidence also suggests the southward subduction of the Eurasian lithosphere beneath the Tibetan block. A significant compressional tectonism due to the subduction of the Indian and Eurasian lithosphere beneath the Tibetan block resulted in the uplift of the whole Tibetan Plateau. The continent-to-continent collision between the Arabian and Eurasian plates uplifted the Iranian block, which is separated from the Eurasian plate by the strike-slip fault systems with major sections of the Herat, Chakaneh-Neyshabur, Bakharden-Quchan, Kopet Dagh and Mosha faults. The extensional tectonism occurred along the Mid-Indian oceanic rift zone and formed also the Baikal Rift Zone. Another significant feature within the study area is the Ural Orogen, which represents the oldest known orogenic structure mostly deeply buried into younger sediments. The major geological provinces include also continental basins (Indo-Ganges Basin, Tarim Basin and Sichuan Basin) and cratons (North China Carton, Yangtze Craton, Siberian Caron and Yakutai Craton).

\subsection{Data Acquisition}

The topographic heights on land and the bathymetric depths offshore from the SRTM30 database were used to compute the topographic and bathymetric-stripping gravity corrections with a spectral resolution complete to the spherical harmonic degree 180 . These gravity corrections were computed on a $1 \times 1$ arc-deg surface grid. The average density of the upper continental crust $2670 \mathrm{~kg} \cdot \mathrm{m}^{-3}$ [36] was used to compute the topographic gravity correction. The bathymetric-stripping gravity correction was evaluated by applying the seawater density-depth equation [37]. The sediment-stripping gravity correction was calculated using the CRUST1.0 sediment data. The solid topography of the study area 
is shown in Figure 2a. The combined topographic-bathymetric-sediment gravitational contribution within the study area varies between -354 and $753 \mathrm{mGal}$ (see Figure 2b). This contribution is mostly negative offshore, while positive on land with maxima over Himalaya and Tibet.
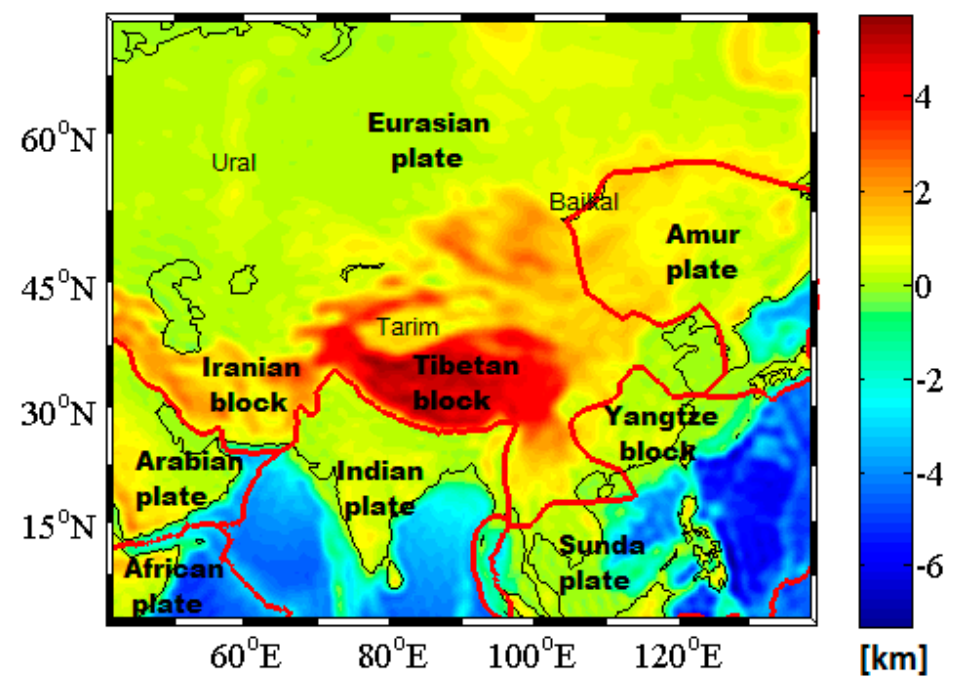

(a)

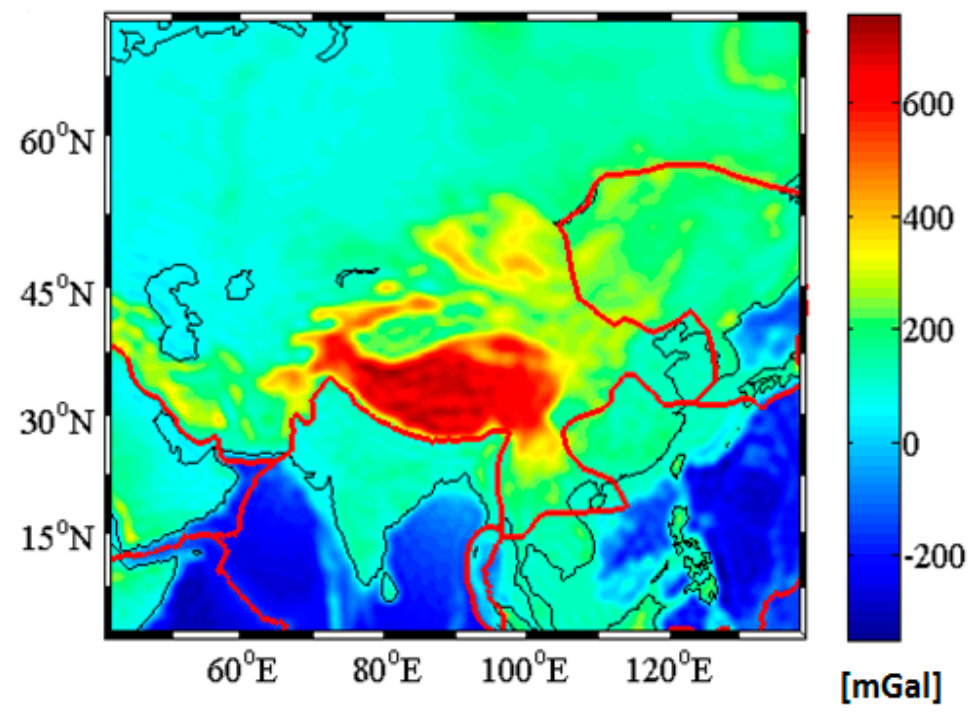

(b)

Figure 2. Regional maps of: (a) the solid topography and (b) the combined topographic-bathymetric gravitational contribution. Tectonic plate boundaries are indicated by red line.

We applied the combined method (Section 2.3) to estimate the Moho density contrast from the GOCE Level 2 EGG_TRF_2 data product [38] over a period from 1st of January until 31st of May 2012 and the CRUST1.0 seismic crustal model. The GOCE data defined in local north oriented frame (LNOF) were transformed into the vertical gravity-gradient gradients (in the geocentric reference frame) and reduced for the normal vertical gravity-gradient computed according to the GRS80 parameters [39]. The GOCE vertical gravity gradients (at respective satellite altitudes) reach positive values up to 1.3 Eötvös (E) as well as negative values $(-1.4 \mathrm{E})$, with the largest horizontal spatial variations across profiles intersecting Tarim and Ganges Basins and Tibetan Orogen (see Figure 3). 


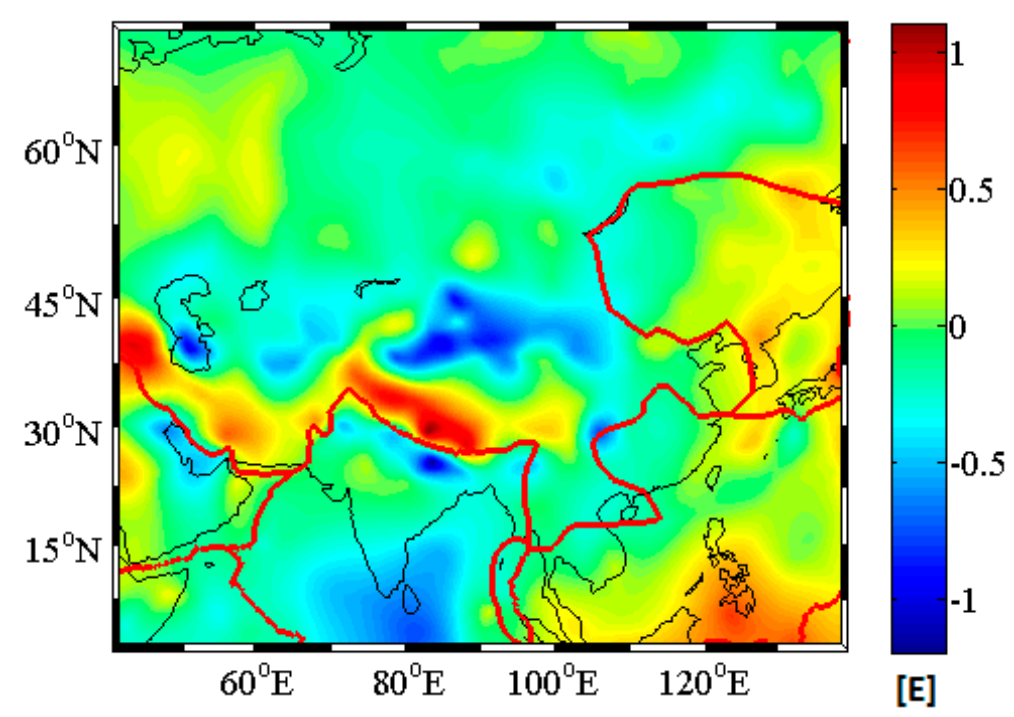

Figure 3. Gravity field and steady-state Ocean Circulation Explorer (GOCE) vertical gravity gradients.

\subsection{Estimation of the Parameter $W$}

The GOCE vertical gravity gradients $V_{r r}$ (Figure 3) were first inverted into the parameters $W$ according to Equation (16). For this purpose, the integral equation was discretized and the (unknown) parameters $W$ were then computed by applying the (least-squares) spherical harmonic analysis. The system of observation equations was solved directly by a matrix inversion and the (zero-order) Tikhonov regularization was applied to stabilize the ill-posed problem. The regularization parameter was estimated by applying the quasi-optimal method [40]. The computed parameters $W$ vary between -21 and $24 \mathrm{mGal}$ (see Figure 4). Since the values $V_{r r}$ and $W$ are highly correlated, their spatial patterns are very similar (see Figures 3 and 4).

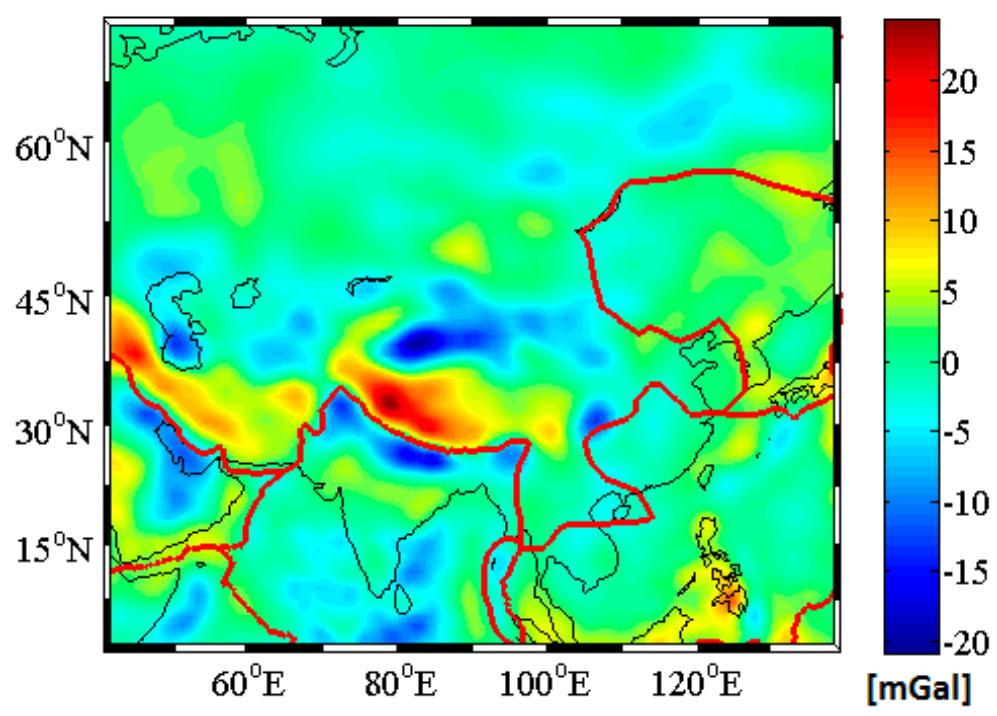

Figure 4. Estimated values of the parameter $W$.

\subsection{Combined Solution for the Moho Parameters}

We further computed the Moho depth and density contrast within the study area on a $1 \times 1$ arc-deg spherical grid by solving the system of condition equations in Equation (22). This solution combines the parameters $W$ estimated from the vertical gravity gradients, the combined topographic-bathymetric 
gravitational contribution computed from the SRTM30 data, the gravitational contribution of sediments estimated using the CRUST1.0 sediment data and the CRUST1.0 Moho parameters $T_{0}$ and $\Delta \rho_{0}$. For the least-squares estimation, the weight matrix was chosen to be the identity matrix. We then repeated the computation for the Moho parameter $T_{0}$ taken from the seismic models GSMM [41] and M13 [42]. Since these two models provide information only on the Moho depth, we adopted the value $\Delta \rho_{0}$ from CRUST1.0. The combined solutions (denoted as: R1_CRUST1.0, R2_GSMM and R3_M13) are shown in Figure 5 and their statistical summaries are given in Table 1 (for the Moho depth) and Table 2 (for the Moho density contrast).

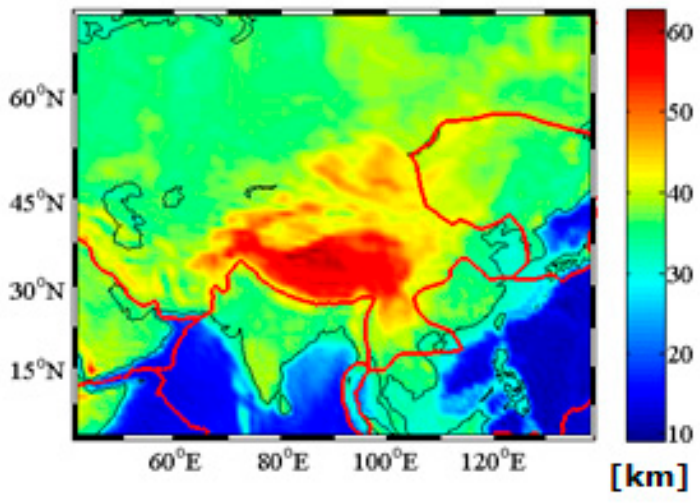

[km]

(a)
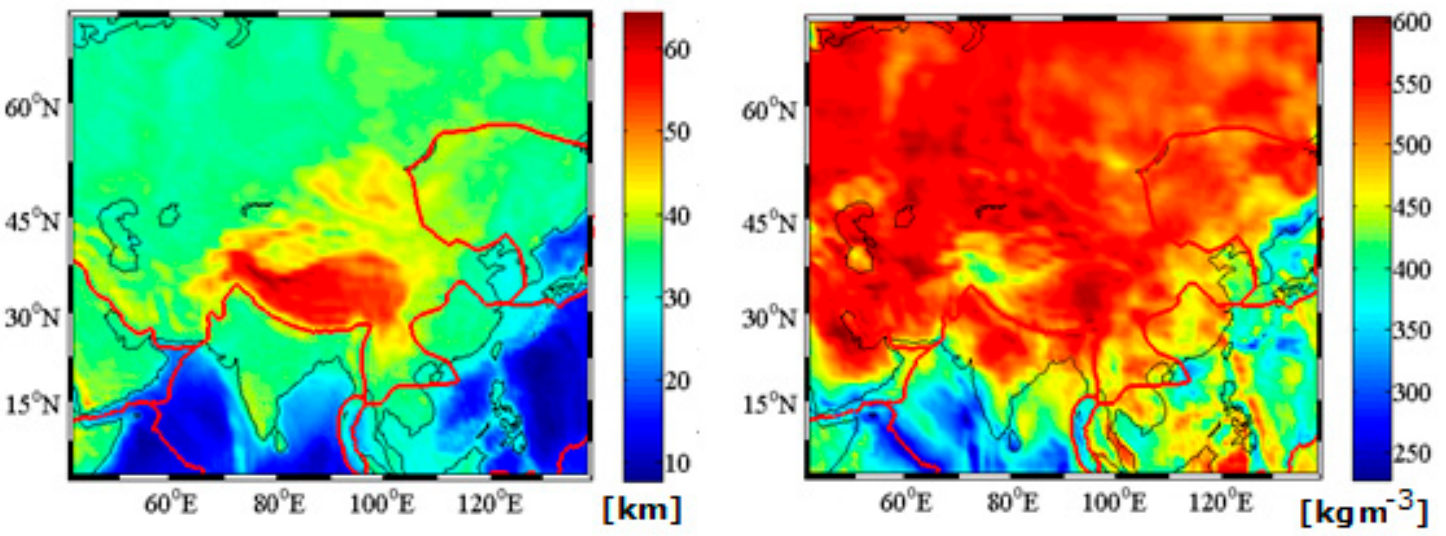

(b)
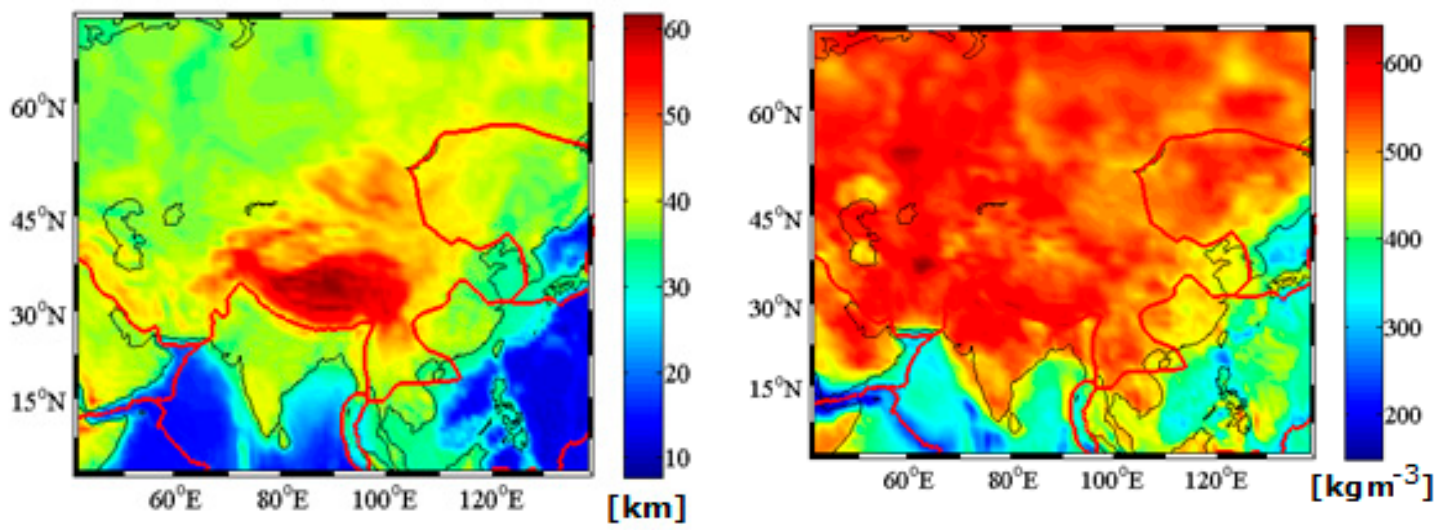

(c)

Figure 5. Combined solutions for the Moho depth (left panels) and density contrast (right panels): (a) R1_CRUST1.0; (b) R2_GSMM and (c) R3_M13. 
Table 1. Statistics of the Moho depth solutions.

\begin{tabular}{ccccc}
\hline Combined Solution & Min $(\mathbf{k m})$ & Max $(\mathbf{k m})$ & Mean $\mathbf{( k m )}$ & STD $(\mathbf{k m})$ \\
\hline R1_CRUST1.0 & 7.4 & 62.4 & 33.2 & 10.3 \\
R2_GSMM & 7.7 & 64.2 & 32.2 & 9.9 \\
R3_M13 & 10.2 & 61.6 & 34.5 & 10.3 \\
\hline
\end{tabular}

Table 2. Statistics of the Moho density contrast solutions.

\begin{tabular}{|c|c|c|c|c|}
\hline Combined Solution & $\operatorname{Min}\left(\mathrm{kg} \cdot \mathrm{m}^{-3}\right)$ & $\operatorname{Max}\left(\mathrm{kg} \cdot \mathrm{m}^{-3}\right)$ & Mean $\left(\mathrm{kg} \cdot \mathrm{m}^{-3}\right)$ & STD $\left(\mathrm{kg} \cdot \mathrm{m}^{-3}\right)$ \\
\hline R1_CRUST1.0 & 166 & 624 & 166 & 87 \\
\hline R2_GSMM & 211 & 602 & 211 & 75 \\
\hline R3_M13 & 149 & 640 & 149 & 87 \\
\hline
\end{tabular}

As seen in Figure 5, all three results exhibit a similar spatial pattern in estimated values of the Moho depth and density contrast. The most pronounced feature in the Moho geometry is the contrast between a thin oceanic crust compared to a thicker continental crustal structure with the maximum Moho deepening under orogens of Himalaya and Tibet. The most pronounced pattern in the Moho density contrast is related with significant differences between the density contrast under continental and oceanic crustal structures. In this case, however, the density contrast under orogens is not significantly enhanced. Instead, the Moho density contrast along mid-oceanic rift zones is more pronounced with respect to the density contrast under the remaining oceanic crust. As seen, the Moho density contrast under the oceanic crust varies typically from 200 to $400 \mathrm{~kg} \cdot \mathrm{m}^{-3}$ with minima along mid-oceanic rift zones. The Moho density contrast under the continental crust mostly exceeds $450 \mathrm{~kg} \cdot \mathrm{m}^{-3}$. Despite these similarities between all three combined results, some more localized differences between them could be recognized. However, these differences are within the level of expected uncertainties of the estimated Moho parameters. It was demonstrated, for instance, by [43] that the Moho depth uncertainties (estimated using seismic data) beneath Europe could regionally exceed $10 \mathrm{~km}$, with an average error about $4 \mathrm{~km}$. Even larger errors are to be considered at regions where seismic data are sparse or absent. Similarly, relative errors $10 \%$ or larger could be expected in estimated values of the Moho density contrast.

In our numerical realization we disregarded the density heterogeneities within the remaining crust down to the Moho interface, because the CRUST1.0 data of consolidated crustal density layers are not sufficiently accurate. To demonstrate this, we computed the combined gravitational contribution of topography, bathymetry, sediments and consolidated crust. This contribution varies between -514 to $943 \mathrm{mGal}$, with a mean $198 \mathrm{mGal}$ and a standard deviation $265 \mathrm{mGal}$ (see Figure 6a). We then used these values to estimate the Moho depth and density contrast. The application of the consolidated crust-stripping gravity correction introduced a systematic bias in estimated values of the Moho depth. As seen in Figure 6b, the Moho depth in this case varies between 1.6 and $71.2 \mathrm{~km}$, with a mean $41.3 \mathrm{~km}$ and a standard deviation $11.1 \mathrm{~km}$. This mean Moho depth differs significantly from the Moho solutions obtained without applying the consolidated crust-stripping gravity correction ( $c f$. Table 1). The Moho density contrast is shown in Figure 6c. It varies between 159 and $712 \mathrm{~kg} \cdot \mathrm{m}^{-3}$, with a mean $537 \mathrm{~kg} \cdot \mathrm{m}^{-3}$ and a standard deviation $65 \mathrm{~kg} \cdot \mathrm{m}^{-3}$. The comparison of these values with the Moho density contrast estimated without applying the consolidated crust-stripping gravity correction (cf. Table 2 ) indicates again the presence of a large systematic bias. 


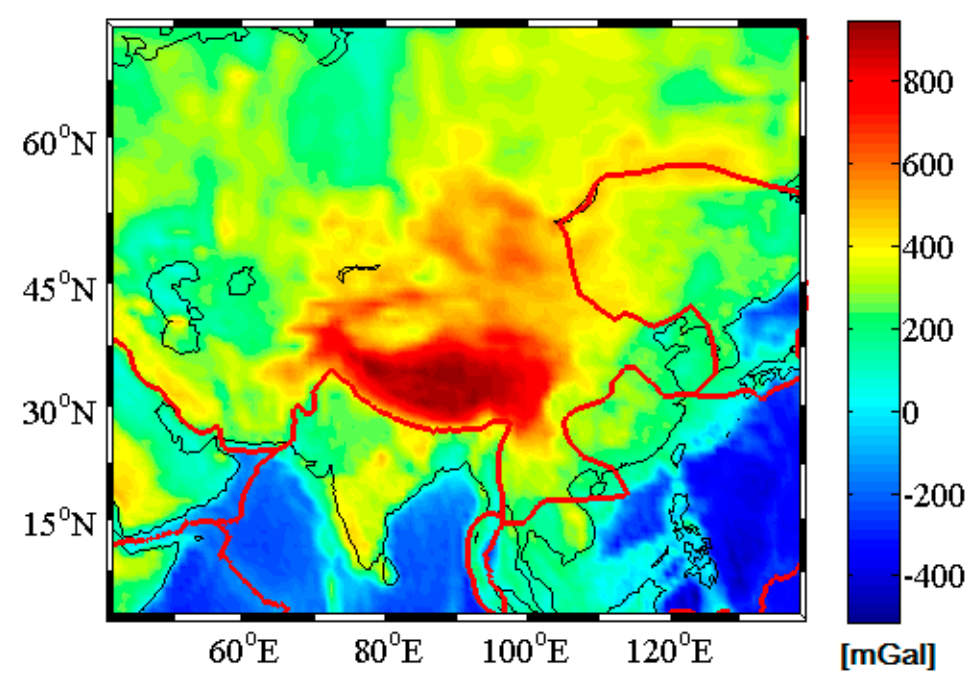

(a)

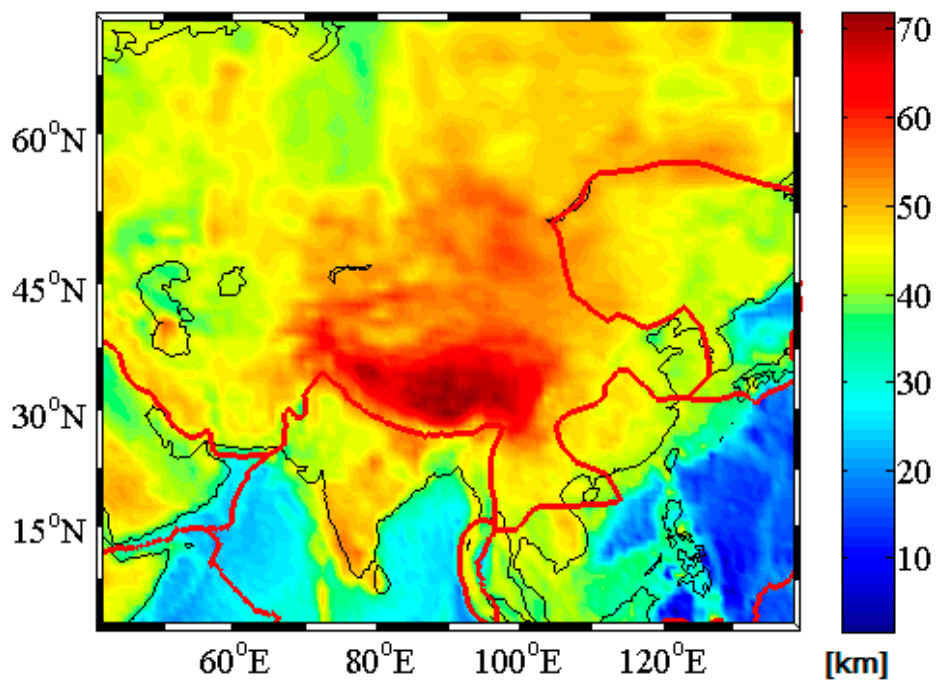

(b)

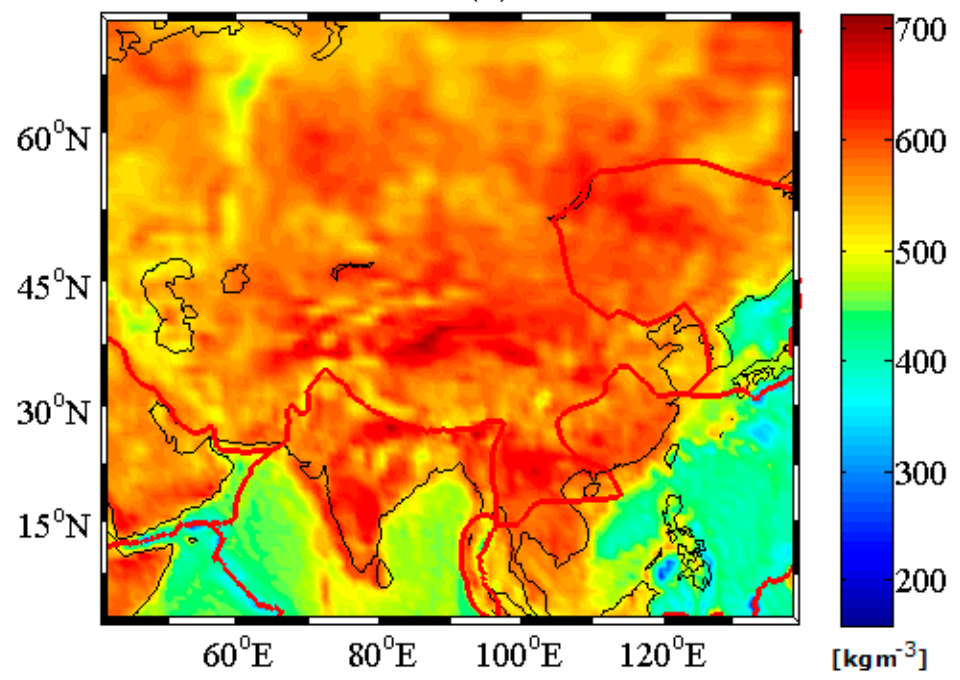

(c)

Figure 6. Effect of the consolidated crust-stripping gravity correction to Moho parameters: (a) the combined gravitational contribution of topography, bathymetry, sediments and consolidated crust. The estimated values of: (b) Moho depth and (c) Moho density contrast. 


\subsection{Validation of Results}

To validate the combined results presented in Figure 5, we compared the Moho density contrast with the CRUST1.0 and KTH1.0 [44] models (see Figure 7 and statistics in Table 3). In addition, we compared the Moho depth with the CRUST1.0, KTH1.0, GSMM, M13 and GEMMA [45] models (see Figure 8 and statistics in Table 4). The Moho density contrast differences are plotted in Figure 9 and their statistical summary is given in Table 5. For completeness, we also provided a statistical summary for the Moho depth differences in Table 6.
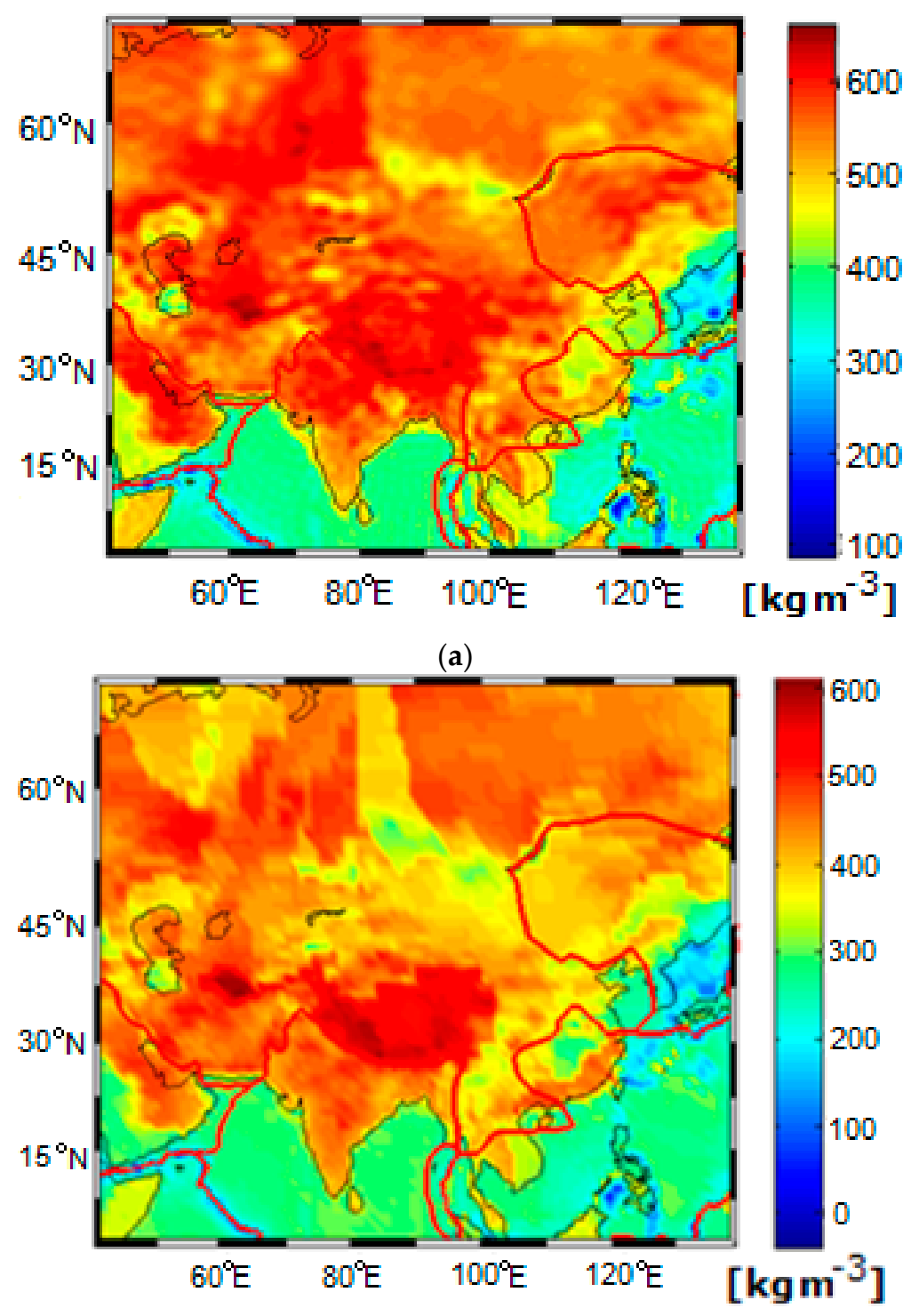

(b)

Figure 7. Moho density contrast from: (a) the global seismic crustal model CRUST1.0 and (b) the global gravimetric Moho model KTH1.0. 


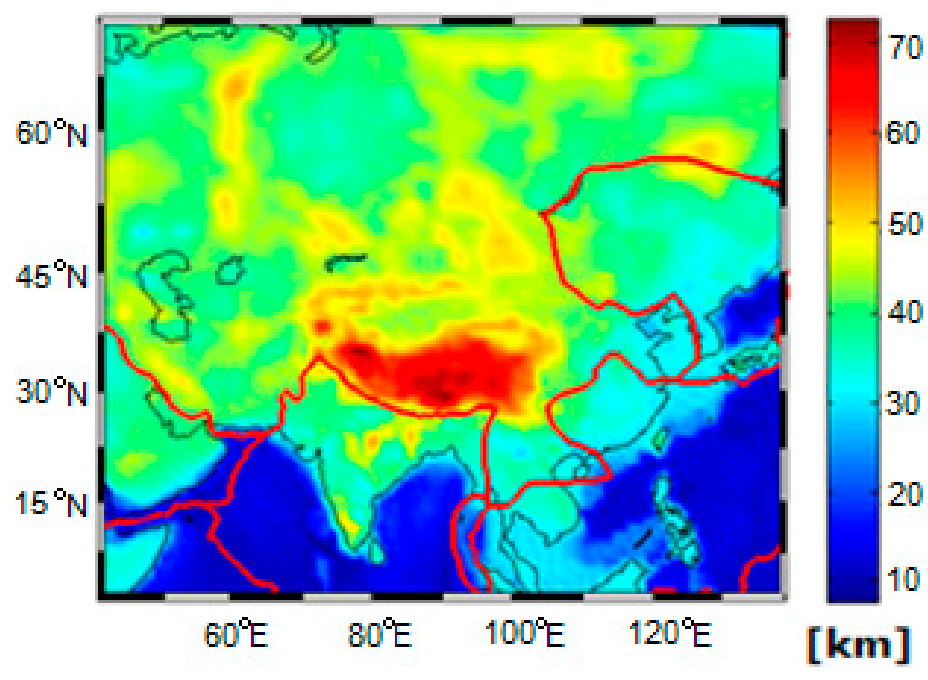

(a)

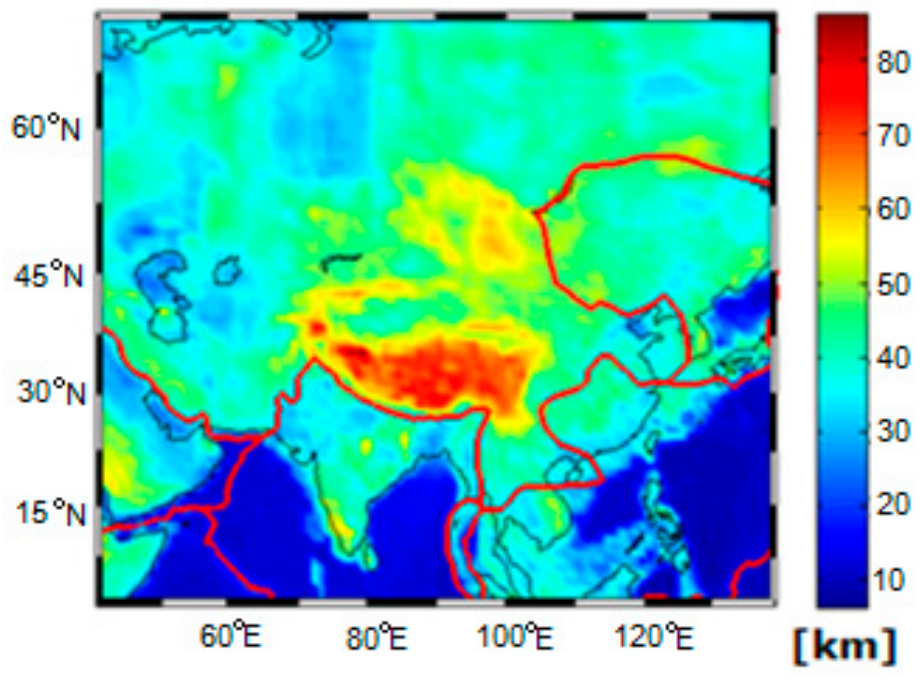

(b)

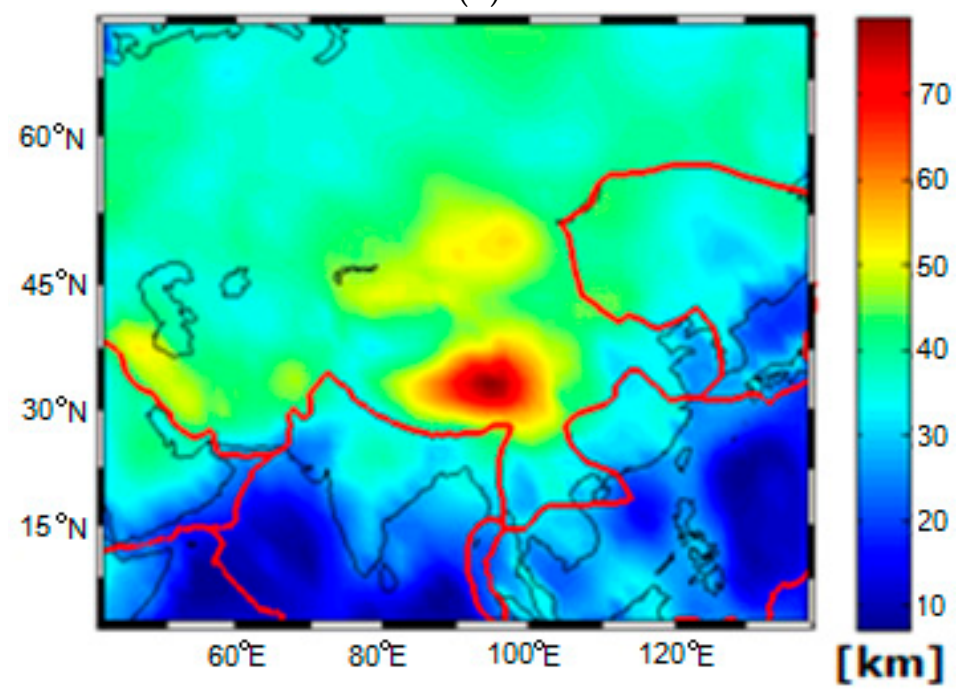

(c)

Figure 8. Cont. 


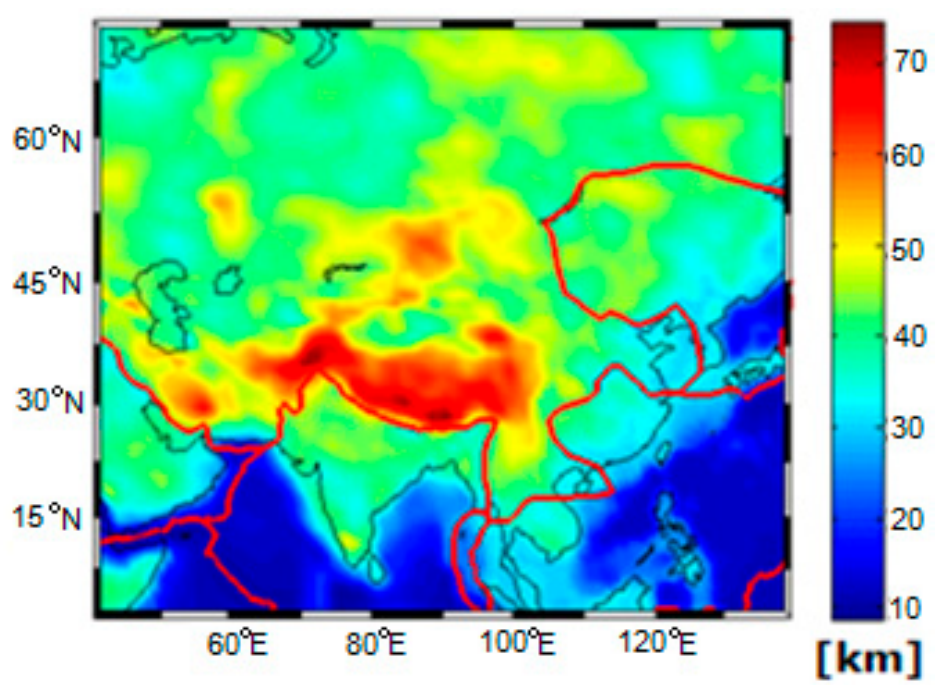

(d)

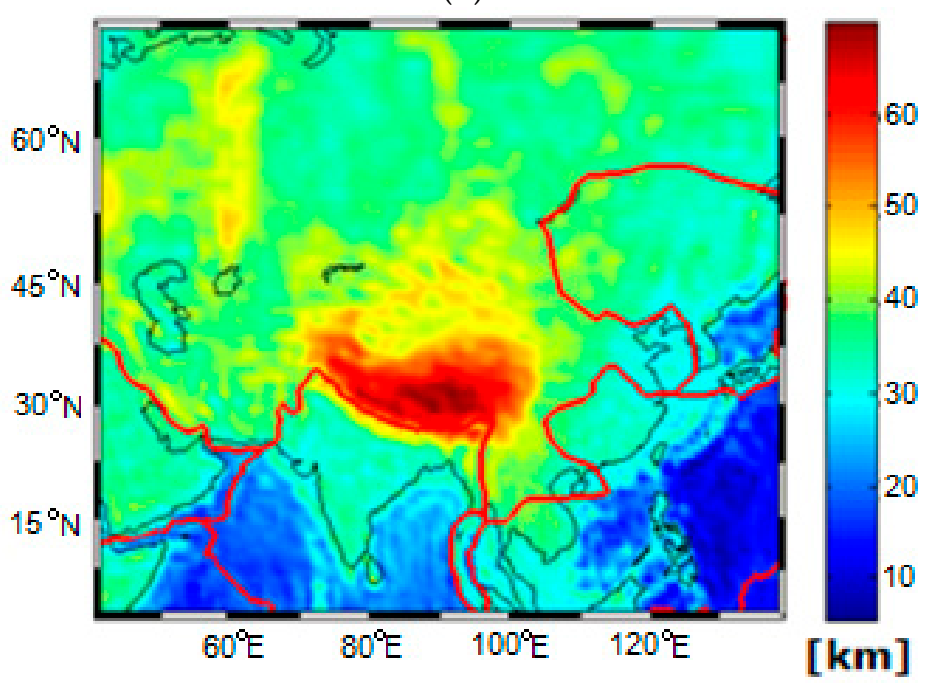

(e)

Figure 8. Moho depth from: (a) CRUST1.0; (b) KTH1.0; (c) GSMM; (d) M13 and (e) GEMMA models.

As seen in Table 5, all three combined solutions for the Moho density contrast better agree (by means of the RMS of differences) with the CRUST1.0 seismic model than with the KTH1.0 combined gravimetric-seismic model. Moreover, the R2_GSMM combined solution relatively poorly reproduces the Moho density contrast under Himalaya and most of Tibet ( $c f$. Figure 9b). These large density contrast differences are explained by an unrealistically shallow Moho of the GSMM seismic model (see Figure 8c) under these orogens. Despite the R2_GSMM combined solution has the best RMS fit with the CRUST1.0 and KTH1.0 models ( $c f$. Table 5), this combined solution is likely very inaccurate in these areas. The R1_CRUST1.0 and R3_M13 combined models are, on the other hand, very similar by means of their spatial pattern as well as their RMS fit with testing models. This finding is also confirmed by the results of the Moho depth modeling. As seen in Table 6, the RMS fit of these two combined solutions with the Moho depth from the CRUST1.0, KTH1.0, M13 and GEMMA models are similar. Interestingly, however, the GSMM Moho depth errors in Himalaya and Tibet are to a large extent reduced in the R2_GSMM combined solution. This is due to the fact that the condition equations in Equation (18) were specified for the mean values of the Moho parameters $T_{0}$ and $\Delta \rho_{0}$. The formulation of condition equations for mean Moho parameters has also practical implications, because in this way we could to some extent reduce errors in estimated Moho parameters over areas with insufficient seismic-data coverage. 

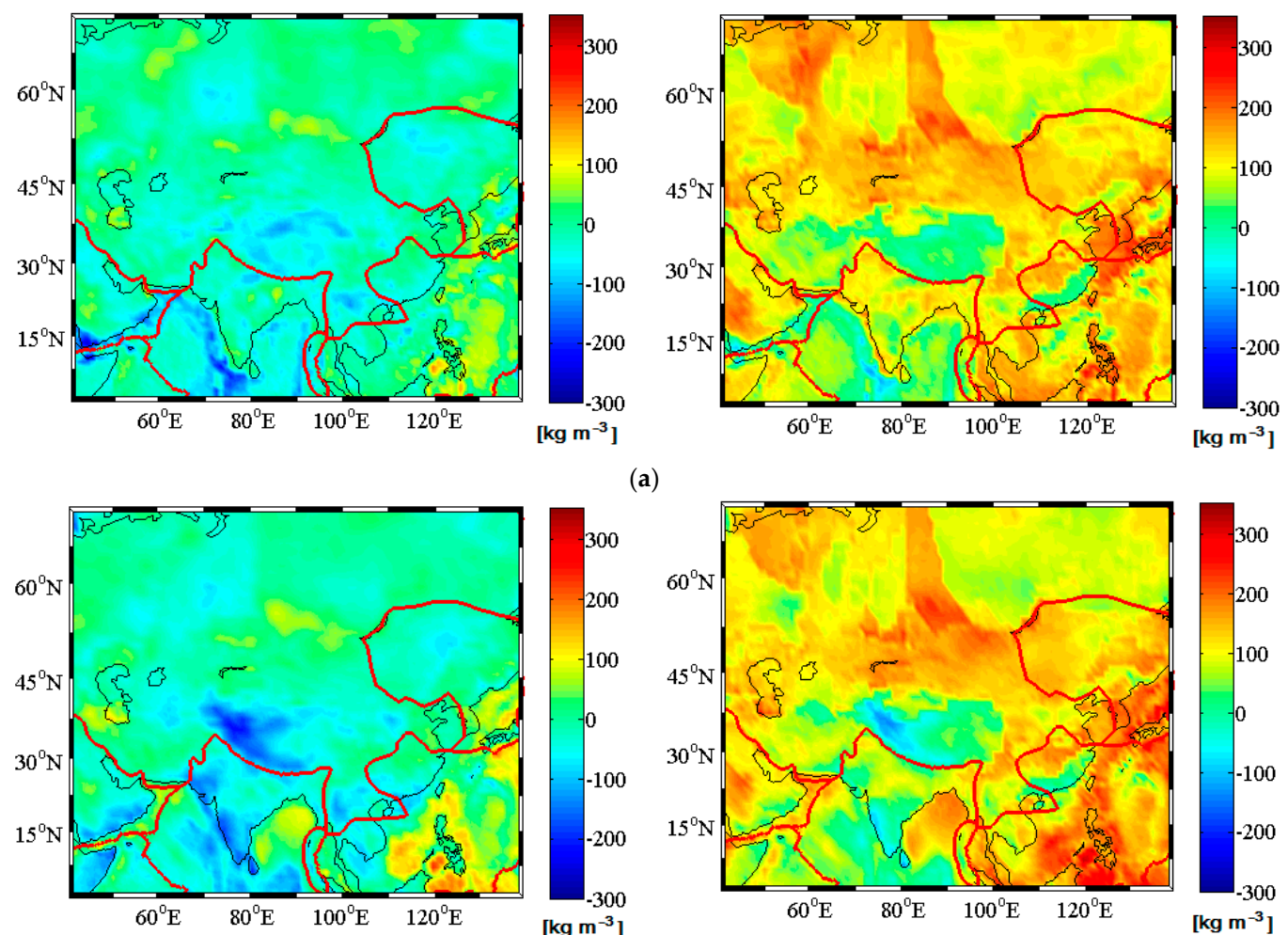

(a)

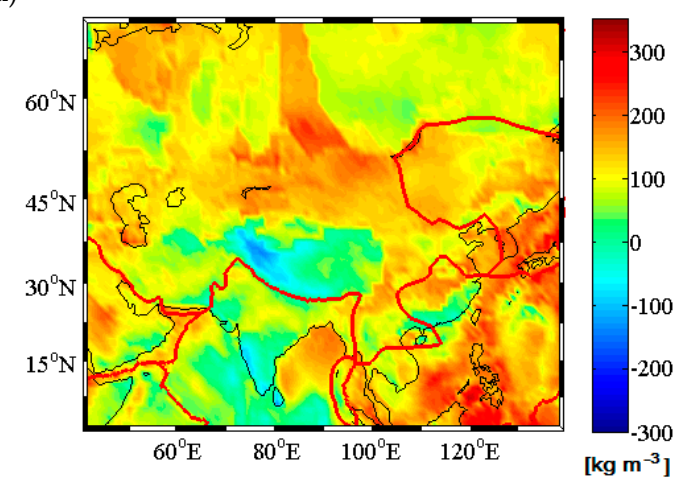

(b)
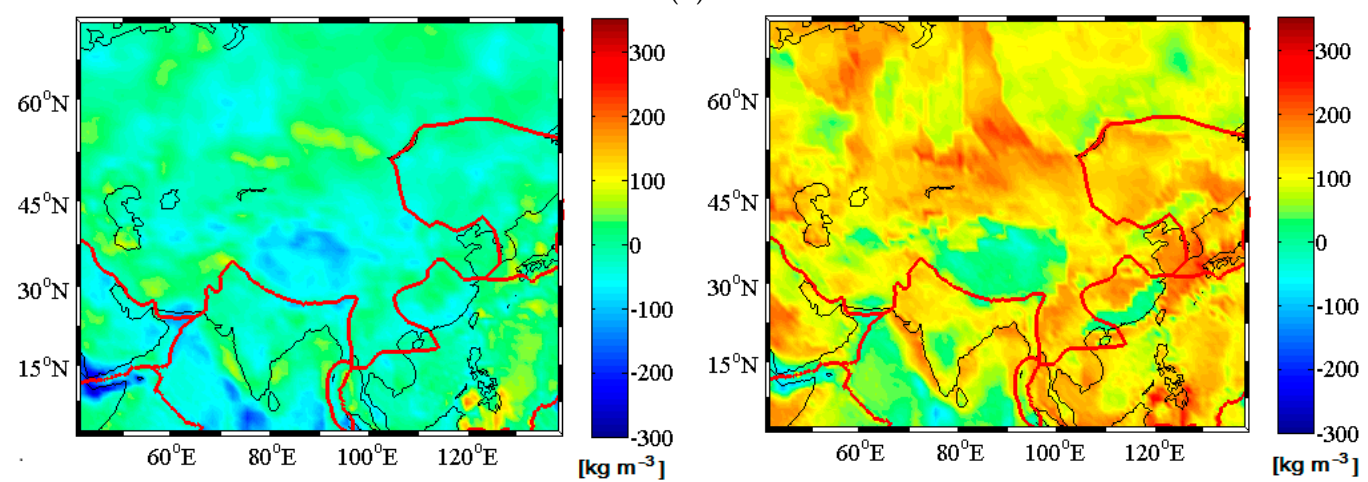

(c)

Figure 9. Moho density contrast differences of the combined solutions: (a) R1_CRUST1.0; (b) R2_GSMM and (c) R3_M13 taken with respect to the CRUST1.0 (left panels) and KTH1.0 models (right panels).

Table 3. Statistics of the Moho density contrast from the CRUST1.0 and KTH1.0 models.

\begin{tabular}{ccccc}
\hline Model & Min $\left.\mathbf{( k g} \cdot \mathbf{m}^{-\mathbf{3}}\right)$ & Max $\left.\mathbf{( k g} \cdot \mathbf{m}^{-\mathbf{3}}\right)$ & Mean $\left.\mathbf{( k g} \cdot \mathbf{m}^{-\mathbf{3}}\right)$ & $\mathbf{S T D ~} \mathbf{( k g} \cdot \mathbf{~ m}^{-\mathbf{3}} \mathbf{)}$ \\
\hline CRUST1.0 & 88 & 694 & 495 & 95 \\
KTH1.0 & -40 & 610 & 374 & 94 \\
\hline
\end{tabular}

Table 4. Statistics of the Moho depth from the CRUST1.0, KTH1.0, GSMM, M13 and GEMMA models.

\begin{tabular}{ccccc}
\hline Model & Min $(\mathbf{k m})$ & Max $(\mathbf{k m})$ & Mean $\mathbf{( k m )}$ & STD $(\mathbf{k m})$ \\
\hline CRUST1.0 & 7.7 & 72.6 & 34.1 & 12.8 \\
KTH1.0 & 6.2 & 85.8 & 35.1 & 13.8 \\
GSMM & 7.0 & 78.9 & 32.6 & 11.4 \\
M13 & 8.7 & 74.4 & 35.4 & 13.2 \\
GEMMA & 5.5 & 69.7 & 33.5 & 10.1 \\
\hline
\end{tabular}


Table 5. Statistics of the Moho density contrast differences.

\begin{tabular}{|c|c|c|c|c|}
\hline Differences & $\operatorname{Min}\left(\mathrm{kg} \cdot \mathrm{m}^{-3}\right)$ & $\operatorname{Max}\left(\mathrm{kg} \cdot \mathrm{m}^{-3}\right)$ & Mean $\left(\mathrm{kg} \cdot \mathrm{m}^{-3}\right)$ & $\operatorname{RMS}\left(\mathbf{k g} \cdot \mathbf{m}^{-3}\right)$ \\
\hline R1_CRUST1.0 - CRUST1.0 & -253 & 200 & -13 & 43 \\
\hline R1_CRUST1.0 - KTH1.0 & -112 & 292 & 106 & 119 \\
\hline R2_GSMM - CRUST1.0 & -253 & 200 & -13 & 42 \\
\hline R2_GSMM - KTH1.0 & -98 & 301 & 106 & 118 \\
\hline R3_M13 - CRUST1.0 & -227 & 245 & -11 & 56 \\
\hline R3_M13 - KTH1.0 & -157 & 353 & 109 & 125 \\
\hline
\end{tabular}

Table 6. Statistics of the Moho depth differences.

\begin{tabular}{ccccc}
\hline Differences & Min $\mathbf{( k m )}$ & Max $\mathbf{( k m )}$ & Mean $\mathbf{( k m )}$ & RMS $(\mathbf{k m})$ \\
\hline R1_CRUST1.0 - CRUST1.0 & -20.1 & 23.1 & -0.1 & 5.5 \\
R1_CRUST1.0 - KTH1.0 & -25.2 & 19.8 & -1.2 & 6.4 \\
R1_CRUST1.0 - GSMM & -21.8 & 25.8 & 1.2 & 5.7 \\
R1_CRUST1.0 - M13 & -23.9 & 22.5 & -1.5 & 6.0 \\
R1_CRUST1.0 - GEMMA & -23.3 & 13.0 & 0.4 & 3.9 \\
R2_GSMM - CRUST1.0 & -23.3 & 21.5 & -1.9 & 5.9 \\
R2_GSMM - KTH1.0 & -35.5 & 18.3 & -2.8 & 6.9 \\
R2_GSMM - GSMM & -29.7 & 18.3 & -0.3 & 5.5 \\
R2_GSMM - M13 & -29.1 & 21.2 & -3.1 & 6.7 \\
R2_GSMM - GEMMA & -26.3 & 11.4 & -1.3 & 4.3 \\
R3_M13 - CRUST1.0 & -18.8 & 24.3 & 1.1 & 5.7 \\
R3_M13 - KTH1.0 & -27.9 & 21.1 & 0.1 & 6.3 \\
R3_M13 - GSMM & -21.5 & 25.9 & 2.5 & 6.2 \\
R3_M13 - M13 & -21.0 & 23.9 & -0.1 & 5.7 \\
R3_M13 - GEMMA & -22.0 & 16.2 & 1.7 & 4.3 \\
\hline
\end{tabular}

\section{Summary and Concluding Remarks}

We have developed the combined method for a determination of the Moho parameters from the GOCE in-orbit gravity gradients and constrained using seismic crustal model. We applied this method to investigate the Moho density contrast under most of Eurasia including surrounding continental and oceanic areas. The input data used for computation involved the topographic information from the SRTM on land, the bathymetric information derived from processing the satellite-altimetry data offshore, the sediment density and thickness information from the CRUST1.0 data and the vertical gravity gradients obtained from processing the GOCE satellite observables. The least-squares technique, applied for a regional Moho recovery, was formulated for the system of condition equations and solved based on finding the minimum-norm solution in order to obtain an optimal fit between gravimetric and seismic models. The condition equations were defined for mean values of seismic Moho parameters in order to suppress errors from areas with insufficient seismic-data coverage.

Our results confirmed large variations of the Moho density contrast with minima along the mid-oceanic rift zones and maxima under most of continental crustal structures. These results have a relatively good agreement with the CRUST1.0 and KTH1.0 models, but differ substantially from some previously published results of gravimetric studies. The most significant inconsistency was found in overestimated values of the Moho density contrast under Tibet and Himalaya, which according to $[23,30]$ could reach $800 \mathrm{~kg} \cdot \mathrm{m}^{-3}$ or even more. In more recent study [43], however, much smaller values of the Moho density contrast were estimated (i.e., the KTH1.0 model). Moreover, the Moho density contrast according to [46] could hardly exceed $600 \mathrm{~kg} \cdot \mathrm{m}^{-3}$ and much smaller values of the Moho density contrast were also reported in various seismic studies. In this study, we have confirmed these findings by showing that the Moho density contrast under most of the Eurasian continental crust is typically very uniform with most of the values being within a range from 400 to $600 \mathrm{~kg} \cdot \mathrm{m}^{-3}$. 
Acknowledgments: The second author acknowledges the Quaid-i-Azam University, Islamabad, Pakistan for a financial support under faculty development program. The National Science Foundation of China (NSFC) is cordially acknowledged for a financial support by the research grant 41429401 . We also acknowledge the Czech Ministry of Education, Youth and Sport for a financial support by the National Program of Sustainability, Project No.: LO1506.

Author Contributions: Mehdi Eshagh conceived and designed the experiments and performed numerical experiments; Matloob Hussain interpreted the results, Mohsen Romeshkani provided the GOCE in-orbit data; and Robert Tenzer analyzed the results and complied the manuscript.

Conflicts of Interest: The authors declare no conflict of interest. The founding sponsors had no role in the design of the study; in the collection, analyses, or interpretation of data; in the writing of the manuscript, and in the decision to publish the results.

\section{References}

1. Dixon, T.H.; Naraghi, M.; McNutt, M.K.; Smith, S.M. Bathymetric prediction from Seasat altimeter data. J. Geophys. Res. 1983, 88, 1563-1571. [CrossRef]

2. Cazenave, A.; Schaeffer, P.; Berge, M.; Brossier, C.; Dominh, K.; Gennero, M.C. High-resolution mean sea surface computed with altimeter data of ERS-1 (geodetic mission) and Topex-Poseidon. Geophys. J. Int. 1996, 125, 696-704. [CrossRef]

3. Sandwell, D.T.; Smith, W.H.F. Marine gravity anomaly from Geosat and ERS 1 satellite altimetry. J. Geophys. Res. Solid Earth 1997, 102, 10039-10054. [CrossRef]

4. Reigber, C.; Bock, R.; Forste, C.; Grunwaldt, L.; Jakowski, N.; Lühr, H.; Schwintzer, P.; Tilgner, C. CHAMP Phase-B Executive Summary; GFZ Scientific Technical Report STR96/13; GeoForschungsZentrum (GFZ): Potsdam, Germany, 1996.

5. Reigber, C.; Schwintzer, P.; Lühr, H. The CHAMP geopotential mission. Boll. Geofis. Teor. Appl. 1999, 40, 285-289.

6. Reigber, C.; Lühr, H.; Schwintzer, P. CHAMP mission status. Adv. Space Res. 2002, 30, 129-134. [CrossRef]

7. Tapley, B.D.; Bettadpur, S.; Watkins, M.; Reigber, C. The gravity recovery and climate experiment: Mission overview and early results. Geophys. Res. Lett. 2004, 31, L09607. [CrossRef]

8. Drinkwater, M.R.; Floberghagen, R.; Haagmans, R.; Muzi, D.; Popescu, A. GOCE: ESA's first Earth Explorer Core mission. In Earth Gravity Field_From Space-From Sensors to Earth Science; Beutler, G., Drinkwater, M.R., Rummel, R., Von Steiger, R., Eds.; Space Sciences Series of ISSI; Springer: Dordrecht, The Netherlands, 2003; Volume 18, pp. 419-432.

9. Floberghagen, R.; Fehringer, M.; Lamarre, D.; Muzi, D.; Frommknecht, B.; Steiger, C.; Piñeiro, J.; da Costa, A. Mission design, operation and exploitation of the gravity field and steady-state ocean circulation explorer mission. J. Geod. 2011, 85, 749-758. [CrossRef]

10. Aitken, A.; Salmon, M.; Kennett, B. Australia's Moho: A test of usefulness of gravity modelling for the determination of Moho depth. Tectonophysics 2013, 609, 468-479. [CrossRef]

11. Van der Meijde, M.; Juliá, J.; Assumpcáo, M. Gravity derived Moho for South America. Tectonophysics 2013, 609, 456-467. [CrossRef]

12. Mariani, P.; Braitenberg, C.; Ussami, N. Explaining the thick crust in Paraná basin, Brazil, with satellite GOCE gravity observations. J. South Am. Earth Sci. 2013, 45, 209-223. [CrossRef]

13. Bagherbandi, M.; Sjöberg, L.E. Improving gravimetric-isostatic models of crustal depth by correcting for non-isostatic effects and using CRUST2.0. Earth Sci. Rev. 2013, 117, 29-39. [CrossRef]

14. Tenzer, R.; Chen, W. Regional gravity inversion of crustal thickness beneath the Tibetan plateau. Earth Sci. Inform. 2014, 7, 265-276. [CrossRef]

15. Tenzer, R.; Eshagh, M.; Jin, S. Martian sub-crustal stress from gravity and topographic models. Earth Planet. Sci. Lett. 2015, 425, 84-92. [CrossRef]

16. Bagherbandi, M.; Sjöberg, L.E.; Tenzer, R.; Abrehdary, M. A new Fennoscandian crustal thickness model based on CRUST1.0 and a gravimetric-isostatic approach. Earth Sci. Rev. 2015, 145, 132-145. [CrossRef]

17. Abrehdary, M.; Sjöberg, L.E.; Bagherbandi, M. Combined Moho parameters determination using CRUT1.0 and Vening Meinesz-Moritz method. J. Earth Sci. 2015, 26, 607-616. [CrossRef]

18. Goodacre, A.K. Generalized structure and composition of the deep crust and upper mantle in Canada. J. Geophys. Res. 1972, 77, 3146-3160. [CrossRef]

19. Niu, F.; James, D.E. Fine structure of the lowermost crust beneath the Kaapvaal craton and its implications for crustal formation and evolution. Earth Planet. Sci. Lett. 2002, 200, 121-130. [CrossRef] 
20. Jordi, J. Constraining velocity and density contrasts across the crust-mantle boundary with receiver function amplitudes. Geophys. J. Int. 2007, 171, 286-301.

21. Laske, G.; Masters, G.; Ma, Z.; Pasyanos, M.E. Update on CRUST1.0-A 1-degree global model of Earth's crust. Geophys. Res. Abstr. 2013, 15. EGU2013-2658.

22. Reguzzoni, M.; Sampietro, D. GEMMA: An Earth crustal model based on GOCE satellite data. Int. J. Appl. Earth Obs. Geoinf. 2015, 35, 31-43. [CrossRef]

23. Sjöberg, L.E.; Bagherbandi, M. A method of estimating the Moho density contrast with a tentative application by EGM08 and CRUST2.0. Acta Geophys. 2011, 59, 502-525. [CrossRef]

24. Vening Meinesz, F.A. Une nouvelle méthode pour la réduction isostatique régionale de Í intensité de la pesanteur. Bull. Geod. 1931, 29, 33-51. [CrossRef]

25. Moritz, H. The Figure of the Earth; Wichmann, H.: Karlsruhe, Germany, 1990.

26. Sjöberg, L.E. Solving Vening Meinesz-Moritz inverse problem in isostasy. Geophys. J. Int. 2009, 179, $1527-1536$. [CrossRef]

27. Sjöberg, L.E. On the isostatic gravity anomaly and disturbance and their applications to Vening Meinesz-Moritz inverse problem of isostasy. Geophys. J. Int. 2013, 193, 1277-1282. [CrossRef]

28. Bagherbandi, M.; Sjöberg, L.E. Modelling the density contrast and depth of the Moho discontinuity by seismic and gravimetric-isostatic methods with an application to Africa. J. Afr. Earth Sci. 2012, 68, 111-120.

29. Tenzer, R.; Chen, W.; Jin, S. Effect of Upper Mantle Density Structure on Moho Geometry. Pure Appl. Geophys. 2015, 172, 1563-1583. [CrossRef]

30. Tenzer, R.; Bagherbandi, M.; Vajda, P. Global model of the upper mantle lateral density structure based on combining seismic and isostatic models. Geosci. J. 2013, 17, 65-73. [CrossRef]

31. Tenzer, R.; Bagherbandi, M.; Gladkikh, V. Signature of the upper mantle density structure in the refined gravity data. Comput. Geosci. 2012, 16, 975-986. [CrossRef]

32. Tenzer, R.; Bagherbandi, M.; Sjöberg, L.E.; Novák, P. Isostatic crustal thickness under the Tibetan Plateau and Himalayas from satellite gravity gradiometry data. Earth Sci. Res. J. 2015, 19, 95-107. [CrossRef]

33. Sjöberg, L.E.; Bagherbandi, M.; Tenzer, R. On Gravity Inversion by No-Topography and Rigorous Isostatic Gravity Anomalies. Pure Appl. Geophys. 2015, 172, 2669-2680. [CrossRef]

34. Eshagh, M. Determination of Moho discontinuity from satellite gradiometry data: Linear approach. Geodyn. Res. Int. Bull. 2014, 1, 1-13.

35. Eshagh, M. The effect of spatial truncation error on integral inversion of satellite gravity gradiometry data. Adv. Space Res. 2011, 47, 1238-1247. [CrossRef]

36. Hinze, W. Bouguer reduction density, why 2.67? Geophysics 2003, 68, 1559-1560. [CrossRef]

37. Tenzer, R.; Novák, P.; Gladkikh, V. The bathymetric stripping corrections to gravity field quantities for a depth-dependant model of the seawater density. Mar. Geod. 2012, 35, 198-220. [CrossRef]

38. Gruber, T.; Rummel, R.; Abrikosov, O.; van Hees, R. GOCE Level 2 Product Data Handbook; GO-MA-HPFGS-0110; European Space Agency: Noordwijk, The Netherlands, 2010; Issue 4.3.

39. Moritz, H. Geodetic Reference System 1980. J. Geod. 2000, 74, 128-162. [CrossRef]

40. Hansen, P.C. Regularization Tools version 4.0 for Matlab 7.3. Numer. Algorithms 2007, 46, 189-194. [CrossRef]

41. Meier, U.; Curtis, A.; Trampert, J. Global crustal thickness from neural network inversion of surface wave data. Geophys. J. Int. 2007, 169, 706-722. [CrossRef]

42. Stolk, W.; Kaban, M.; Beekman, F.; Tesauro, M.; Mooney, W.D.; Cloetingh, S. High resolution regional crustal models from irregularly distributed data: Application to Asia and adjacent areas. Tectonophysics 2013, 602, 55-68. [CrossRef]

43. Grad, M.; Tiira, T.; ESC Working Group. The Moho depth map of the European Plate. Geophys. J. Int. 2009, 176, 279-292. [CrossRef]

44. Abrehdary, M. Recovering Moho Parameters Using Gravimetric and Seismic Data. Ph.D. Thesis, KTH Royal Institute of Technology (KTH), Stockholm, Sweden, 2016.

45. Reguzzoni, M.; Sampietro, D.; Sansò, F. Global Moho from the combination of the CRUST2. 0 model and GOCE data. Geophys. J. Int. 2013, 195, 222-237. [CrossRef]

46. Rabbel, W.; Kaban, M.; Tesauro, M. Contrasts of seismic velocity, density and strength across the Moho. Tectonophysics 2013, 609, 437-455. [CrossRef]

(C) 2016 by the authors; licensee MDPI, Basel, Switzerland. This article is an open access article distributed under the terms and conditions of the Creative Commons Attribution (CC-BY) license (http:/ / creativecommons.org/licenses/by/4.0/). 